\title{
Surgical specialty and preoperative medical consultation based on commercial health insurance claims
}

Stephan R. Thilen ${ }^{1 *}$, Alex L. Woersching ${ }^{2}$, Anda M. Cornea ${ }^{3}$, Elliott Lowy ${ }^{2,4}$, Edward M. Weaver ${ }^{5}$ and Miriam M. Treggiari ${ }^{6}$

\begin{abstract}
Background: Surgical patients are sometimes referred for preoperative evaluations by consultants in other medical specialties, although consultations are unnecessary for many patients, particularly for healthy patients undergoing low-risk surgeries. Surgical specialty has been shown to predict usage of preoperative consultations. However, evidence is generally limited regarding factors associated with preoperative consultations. This study evaluates surgical specialty and other predictors of preoperative consultations.
\end{abstract}

Methods: This retrospective cohort study analyzed surgery claims of 7400 privately insured patients in Washington, United States, from eight surgical specialties. We estimated log-Poisson generalized estimating equation models that regress whether a patient received a consultation on surgical specialty and covariates accounting for the data's hierarchical structure with patients nesting within surgeons, and surgeons nesting within provider organizations. Covariates include age, gender, Deyo comorbidity index, surgical risk, and geographic factors.

Results: Overall, $485(6.6 \%)$ patients had a preoperative consultation. The incidence of preoperative consultation varied significantly by surgical specialty. Orthopedics, neurosurgery, and ophthalmology had 3.9 (95\% Cl 2.4, 6.5), 2.3 (95\% Cl 1.1, 4.5), and 2.3 (95\% Cl 1.1, 4.6) times greater adjusted likelihoods of preoperative consultation than general surgery, respectively. The adjusted likelihoods of consultation for gynecology, urology, otolaryngology, and vascular surgery were not statistically different from general surgery. The following covariates were associated with greater likelihood of preoperative consultation: greater age, higher surgical risk, having one or more comorbidities vs. none, and small rural towns vs. urban areas. More than $75 \%$ of all consultations were provided to patients with a Deyo comorbidity index of 0 or 1 . Low surgical risk patients had $0.3(95 \% \mathrm{Cl} 0.3,0.5)$ times the likelihood of preoperative consultation of intermediate and high-risk patients overall.

Conclusions: The likelihood of preoperative consultation varied fourfold (an absolute 9\% points) across surgical specialties. Most consultations were provided to patients with low comorbidity and with low or intermediate surgical risk. To improve usage of preoperative consultations as an evidence-based practice, future research should determine how the health outcomes effects of preoperative consultations vary depending on comorbidity burden and surgical risk.

\footnotetext{
* Correspondence: sthilen@uw.edu; sthilen@yahoo.com

${ }^{1}$ Department of Anesthesiology \& Pain Medicine, University of Washington,

325 Ninth Ave, Box 359724, Seattle, WA 98104, USA

Full list of author information is available at the end of the article
}

(c) The Author(s). 2018 Open Access This article is distributed under the terms of the Creative Commons Attribution 4.0 International License (http://creativecommons.org/licenses/by/4.0/), which permits unrestricted use, distribution, and reproduction in any medium, provided you give appropriate credit to the original author(s) and the source, provide a link to the Creative Commons license, and indicate if changes were made. The Creative Commons Public Domain Dedication waiver (http://creativecommons.org/publicdomain/zero/1.0/) applies to the data made available in this article, unless otherwise stated. 


\section{Background}

Prior to surgical procedures, all patients undergo preoperative and pre-anesthetic evaluations by their surgeons and anesthesia providers. In the Unites States (US), global fees for surgeons and anesthesiologists compensate for those evaluations. Surgeons and anesthesia providers refer a subset of surgical patients for preoperative evaluations by consultants in other medical specialties, which the consultant separately bills for and may initiate downstream testing and care at additional expense. Evidence is limited about the appropriateness of preoperative consultation usage and the value of the resources expended on consultations.

Previous studies have reported wide variability in usage of preoperative medical consultation (Fleisher et al. 2009; Evaluation ASoATFoP 2002), which is consistent with the absence of clear recommendations from evidence-based practice guidelines directing how to select surgical patients for referral to other specialties (Katz et al. n.d.; Clelland et al. 1996; Auerbach et al. 2007; Wijeysundera et al. 2010). Indeed, a survey of anesthesiologists and surgeons involved in referrals for preoperative consultations indicated substantial disagreement among the specialties as to the reasons for obtaining consultations (Katz et al. 1998). Evidence is also varied about the risk factors that trigger referral for preoperative consultation. Previous studies have suggested that comorbidity burden is an important determinant (Auerbach et al. 2007; Wijeysundera et al. 2010); however, an analysis of Medicare claims for patients undergoing cataract surgery found that non-medical factors primarily explained variation in usage of preoperative consultations (Thilen et al. 2014).

In an earlier analysis of an integrated health care system, surgical specialty helped predict usage of preoperative consultations (Thilen et al. 2013). The finding has not been assessed for generalizability in other settings. Therefore, we analyzed commercial insurance claims from the Northwest US to test the hypothesis that surgical specialty is an important predictor of referral for preoperative medical consultation among commercially insured patients.

\section{Methods}

The University of Washington Human Subjects Division reviewed this study and determined that it is not a human subject research.

\section{Design, population, and data sources}

We evaluated a retrospective cohort of surgical claims from Premera Blue Cross, a commercial insurance company based in Seattle, Washington
(WA). All patients were Washington State residents, aged 18-80 years old, and had undergone one of 30 a priori selected common inpatient or outpatient surgical procedures in calendar year 2010. We selected surgical procedures to include commonly performed procedures representing a spectrum of surgical risk (see the "Appendix" section for included procedures and their frequencies in the study cohort). We included eight different surgical specialties: general surgery, ophthalmology, gynecology, orthopedics, urology, otolaryngology, neurosurgery, and vascular surgery. Surgical events were nested within surgeons, and surgeons were nested within provider organizations.

We identified eligible procedures by the patient's first occurrence of a Current Procedural Terminology (CPT) code for one of the specified procedures. We identified the primary endpoint-preoperative medical consultation within the 42-day preoperative period-by the presence of any CPT code for outpatient consultation (99242-99245) or inpatient consultation (99252-99255). We included consultations provided by family physicians, general internists, pulmonologists, cardiologists, endocrinologists, or nurse practitioners. We also included office visits modified with an International Classification of Diseases, 9th Revision, Clinical Modification (ICD-9-CM) code v72.81-v72.84, indicating that the visit was a separately billed preoperative evaluation. We chose a period of 42 days preceding surgery to maximize the ability to capture preoperative consultations that may have led to a delay in scheduling the surgical procedure.

\section{Covariates}

We calculated the Deyo comorbidity index using diagnostic codes present within 365 days before surgery (Deyo et al. 1992). The Deyo comorbidity index was used as an ordinal variable with categories 0,1 , 2 , and $\geq 3$. We also calculated the Revised Cardiac Risk Index (RCRI) (Lee et al. 1999), which predicts cardiac complications. However, we did not include the RCRI in the final analyses because very few patients were class III or IV risk $(98.6 \%$ were class I or II), and the RCRI index did not significantly predict consultation after adjusting for the Deyo index. Surgical procedures were categorized into low, intermediate, and high levels of surgical risk. Patient demographics included age and gender. We used the ZIP code of patient residence to allocate patients to seven hospital referral regions (HRRs) (Everett, Olympia, Seattle, Spokane, Tacoma, and Yakima (all WA cities), and Portland, OR) and to determine patient's Rural Urban Commuting Area (RUCA) category (urban, large rural city, small rural town, 
and isolated rural town). HRRs are approximate health care markets for tertiary care with at least one hospital that performs major cardiovascular and neurosurgery procedures (Dartmouth Medical School and Center for the Evaluative Clinical Sciences 1996). RUCA codes are a classification scheme for characterizing all of US ZIP codes according to their urban or rural character (WWAMI Rural Health Research Center n.d.).

\section{Statistical analysis}

We summarized counts of consultation and we ordered them by day preceding surgery up to 42 days before the index surgery. We conducted bivariate analyses to compare characteristics of patients who did or did not undergo preoperative consultation. We estimated the association between preoperative consultation (outcome variable) and surgical specialty (explanatory variable of interest) by fitting a logPoisson generalized estimating equation (GEE) regression model with robust standard errors. GEE permits obtaining marginal population-averaged interpretations of hierarchical data using non-linear link functions. The exponents of beta coefficients from a log-Poisson model are true risk ratios in contrast to the odds ratios produced by a logistic regression. Odds ratios approximate risk ratios but are inflated (i.e., overstate effects) when outcomes are more common or as effects become larger (Kleinman and Norton 2009). Since surgeons are nested within provider organizations without any non-nested clusters, we clustered on provider organization, and the robust standard errors account for clustering at both the provider and organization levels (Betensky et al. 2000). We adjust for potential confounders: age, gender, Deyo comorbidity index, surgical risk, HRRs, and RUCA categories. The log-Poisson model passed model diagnostic tests: the Hosmer-Lemeshow statistic for model misspecification, the Pearson correlation of the raw-scale residuals and predictions, and Pregibon's link test. A two-sided $\alpha$ level of 0.05 was considered for statistical significance. We report effects as relative risks in the text and Table 2 and also report selected absolute adjusted model estimates in the text and Fig. 2 (main effects model only), as specified (hereafter, adjusted likelihoods). All statistical analyses were performed using Stata 14 (Stata Corporation, College Station, TX, USA).

\section{Results}

A total of 7400 unique patients were identified undergoing any of the 30 included procedures ("Appendix" section). The characteristics of the cohort are presented in Table 1. The mean age was 50.9 years
Table 1 Characteristics of patients receiving and not receiving preoperative consultation

\begin{tabular}{|c|c|c|}
\hline & No consultation & Consultation \\
\hline Total, $n(\%)$ & $6915(93.4)$ & 485 (6.6) \\
\hline Age, mean (SD) & $50.5(12.2)$ & $55.5(9.7)$ \\
\hline \multicolumn{3}{|c|}{ Age categories, $n$ (\%) } \\
\hline $18-34$ & $811(97.5)$ & $21(2.5)$ \\
\hline $35-44$ & $1076(97.1)$ & $32(2.9)$ \\
\hline $45-54$ & $1942(93.6)$ & $133(6.4)$ \\
\hline $55-64$ & $2542(91.2)$ & $246(8.8)$ \\
\hline $65-80$ & $544(91.1)$ & $53(8.9)$ \\
\hline \multicolumn{3}{|l|}{ Sex, $n(\%)$} \\
\hline Male & $2743(92.5)$ & $224(7.5)$ \\
\hline Female & $4172(94.1)$ & $261(5.9)$ \\
\hline \multicolumn{3}{|c|}{ Surgeon specialty, n (\%) } \\
\hline General surgery & $1670(96.9)$ & $53(3.1)$ \\
\hline Gynecology & $675(98.3)$ & $12(1.7)$ \\
\hline Urology & $350(92.3)$ & $29(7.7)$ \\
\hline Ophthalmology & $945(96.1)$ & $38(3.9)$ \\
\hline Orthopedics & 2654 (89.3) & $317(10.7)$ \\
\hline Neurosurgery & $113(89.0)$ & $14(11.0)$ \\
\hline Otolaryngology & $448(96.8)$ & $15(3.2)$ \\
\hline Vascular & 60 (89.6) & $7(10.4)$ \\
\hline \multicolumn{3}{|l|}{ Surgical risk, n (\%) } \\
\hline Low & 3928 (95.6) & $179(4.4)$ \\
\hline Intermediate & $2284(89.7)$ & $261(10.3)$ \\
\hline High & $703(94.0)$ & $45(6.0)$ \\
\hline
\end{tabular}

Deyo comorbidity score, $n(\%)$

1

1

2

$4641(94.4)$

$275(5.6)$

$98(8.1)$

$71(9.2)$

$41(8.2)$

Rural Urban Commuting Area category, n (\%)

$\begin{array}{lll}\text { Urban } & 5665(93.3) & 407(6.7) \\ \text { Large rural city } & 589(96.2) & 23(3.8) \\ \text { Small rural town } & 357(90.4) & 38(9.6) \\ \text { Isolated rural town } & 304(94.7) & 17(5.3) \\ \text { Hospital referral region, n (\%) } & & \\ \text { Everett, WA } & 589(93.3) & 42(6.7) \\ \text { Olympia, WA } & 399(98.5) & 6(1.5) \\ \text { Seattle, WA } & 323(97.9) & 7(2.1) \\ \text { Spokane, WA } & 2509(90.2) & 274(9.8) \\ \text { Tacoma, WA } & 1923(94.5) & 111(5.5) \\ \text { Yakima, WA } & 781(96.9) & 25(3.1) \\ \text { Portland, OR } & 391(95.1) & 20(4.9)\end{array}$

All variable distributions are significantly different between the consultation and no consultation groups at $p \leq 0.01$ 
(SD 12.1), and 60\% were female. Overall, 485 (6.6\%) patients underwent preoperative consultation. The distribution of the timing of preoperative consultations during the days preceding surgery showed peaks on weekly intervals, with modes on days 7 and 14 (Fig. 1). The median interval from consultation to surgery was 13 days (interquartile range 7-21).

Table 2 shows unadjusted and adjusted relative risks of patients having a preoperative medical consultation. Figure 2 shows adjusted likelihoods of preoperative medical consultation from the main effects model for each surgical specialty. In the adjusted analysis, orthopedics, neurosurgery, and ophthalmology were associated with 3.9 (95\% CI 2.4, 6.5), 2.3 (95\% CI 1.1, 4.5), and 2.3 (95\% CI 1.1, 4.6) times greater likelihoods of preoperative medical consultation than general surgery (referent with adjusted likelihood $2.9 \% \quad(95 \%$ CI $1.7,4.1)$ ), respectively. Gynecology, urology, otolaryngology, and vascular surgery were not significantly different from general surgery. In the multivariate analysis, the following covariates were associated with greater likelihood of preoperative consultation: older age, higher surgical risk, comorbidities vs. none, and small rural towns vs. urban areas. Non-Seattle hospital referral regions had a 0.2-0.7 times smaller likelihood of preoperative consultation than Seattle (adjusted likelihood 8.6\% (95\% CI 6.5, 10.6\%), except for Everett (the HRR bordering Seattle to the north) which was not significantly different from Seattle (Table 2).

A sensitivity analysis, including only consultations within 30 days prior to surgery, reduced the number of consults by $7.4 \%(n=36)$ and did not meaningfully change our results.

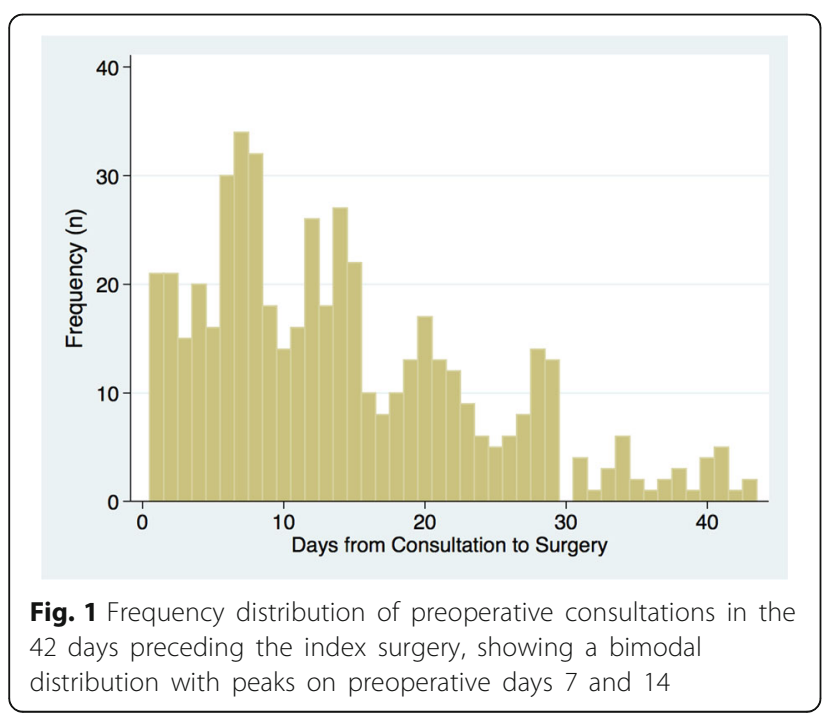

\section{Discussion}

In this cohort of commercially insured patients in the state of Washington, US, we found that some surgical specialties strongly predicted referral for preoperative consultation after adjusting for age, sex, surgical risk, comorbidity burden, and geographic factors. Consistent with our previous work, which studied patients in an integrated health care system (Thilen et al. 2013), we found that ophthalmology and orthopedics were associated with greater usage of preoperative medical consultations relative to general surgery. Neurosurgery, which was not included in the previous report, was also associated with a higher usage of preoperative consultations than general surgery in the current study. Relative to general surgery, we did not find an increased likelihood of preoperative medical consultation among urology patients, although this cohort included only 379 patients. Similar to our previous report, gynecology had the lowest association with preoperative medical consultations, although not significantly different from general surgery. Gynecologists often provide general medical care (Rosenblatt et al. 1998), which supports the view that this care model may reduce usage of preoperative medical consultations for patients undergoing gynecological surgery. In our primary model, low surgical risk patients had two thirds lower likelihood of preoperative consultation than intermediate and high-risk patients.

Preoperative medical consultations were more likely for patients with some comorbidity compared to no comorbidity; however, $>75 \%$ of all consultations were provided to patients with a Deyo comorbidity index of 0 or 1 . It is not clear what considerations lead to usage of preoperative medical consultations for these low-risk patients, who were often undergoing low-risk surgeries. Medical consultations do provide the opportunity to improve documentation of comorbidities, perform risk stratification, optimize factors associated with preexisting medical conditions, and initiate interventions intended to decrease perioperative risk (such as perioperative beta-blockers) (Devereaux et al. 2000; Pausjenssen et al. 2008). However, these potential objectives apply less to patients with minimal or no comorbidities, especially those undergoing low-risk surgeries.

It is possible that while all surgeons are trained to obtain a medical history and perform a complete physical examination, some specialists provide mainly a focused examination and prefer not to personally evaluate the patient for comorbidities. It is possible that some surgeons view this approach as efficient because it allows the surgeon to spend less time on the general medical evaluation and focus more time and effort on the evaluation for and performance of 
Table 2 Crude and adjusted risk ratios for the Association of Surgical Specialty and Preoperative Consultation within 42 days

\begin{tabular}{|c|c|}
\hline & Unadjusted risk ratios (95\% confidence interval) \\
\hline \multicolumn{2}{|l|}{ Surgical specialty (Ref: general surgery) } \\
\hline Gynecology & $0.6(0.3,1.2)$ \\
\hline Urology & $2.4(0.7,8.0)$ \\
\hline Ophthalmology & $1.8(0.9,3.8)$ \\
\hline Orthopedics & $3.4(1.9,6.2)$ \\
\hline Neurosurgery & $3.4(1.5,7.6)$ \\
\hline Otolaryngology & $0.8(0.3,2.0)$ \\
\hline \multirow[t]{2}{*}{ Vascular } & $2.8(1.3,5.9)$ \\
\hline & Adjusted risk ratios ( $95 \%$ confidence interval) \\
\hline \multicolumn{2}{|l|}{ Surgical specialty (Ref: general surgery) } \\
\hline Gynecology & $0.6(0.3,1.2)$ \\
\hline Urology & $1.9(0.8,4.9)$ \\
\hline Ophthalmology & $2.3(1.1,4.6)$ \\
\hline Orthopedics & $3.9(2.4,6.5)$ \\
\hline Neurosurgery & $2.3(1.1,4.5)$ \\
\hline Otolaryngology & $0.6(0.3,1.4)$ \\
\hline Vascular & $1.4(0.7,2.9)$ \\
\hline Low surgical risk (Ref: intermediate and high risk) & $0.3(0.3,0.5)$ \\
\hline Age (10-year change) & $1.2(1.1,1.4)$ \\
\hline \multicolumn{2}{|l|}{ Sex (Ref: male) } \\
\hline Female & $1.0(0.9,1.2)$ \\
\hline \multicolumn{2}{|l|}{ Deyo comorbidity score (Ref: 0) } \\
\hline 1 & $1.4(1.1,1.7)$ \\
\hline 2 & $1.7(1.3,2.1)$ \\
\hline $3+$ & $1.4(1.1,1.9)$ \\
\hline \multicolumn{2}{|l|}{ Rural Urban Commuting Area category (Ref: urban) } \\
\hline Large rural city & $0.8(0.5,1.2)$ \\
\hline Small rural town & $1.6(1.2,2.1)$ \\
\hline Isolated rural town & $0.8(0.5,1.3)$ \\
\hline \multicolumn{2}{|l|}{ Hospital referral region (Ref: Seattle) } \\
\hline Everett, WA & $0.8(0.5,1.3)$ \\
\hline Olympia, WA & $0.2(0.1,0.4)$ \\
\hline Spokane, WA & $0.7(0.6,1.0)$ \\
\hline Tacoma, WA & $0.4(0.2,0.7)$ \\
\hline Yakima, WA & $0.6(0.4,0.9)$ \\
\hline Portland, OR & $0.3(0.2,0.5)$ \\
\hline
\end{tabular}

Significant findings at $p<0.05$ are in italics

the surgical procedures themselves. Future studies are needed to ascertain to what extent this is an explanatory factor for referral to preoperative medical evaluation. To determine the role of preoperative medical consultations in adding value to perioperative care, it will be important to demonstrate improved outcomes such as reduced medical and surgical complications, decreased length of stay, improved recovery (e.g., for outpatient surgery, fewer postoperative emergency room visits), or better patient-centered outcomes. Presumably, such benefits would be most likely for patients with high medical and/or surgical risk. Reports have also shown a potential risk of over-diagnosis among patients referred for cardiology consultation 


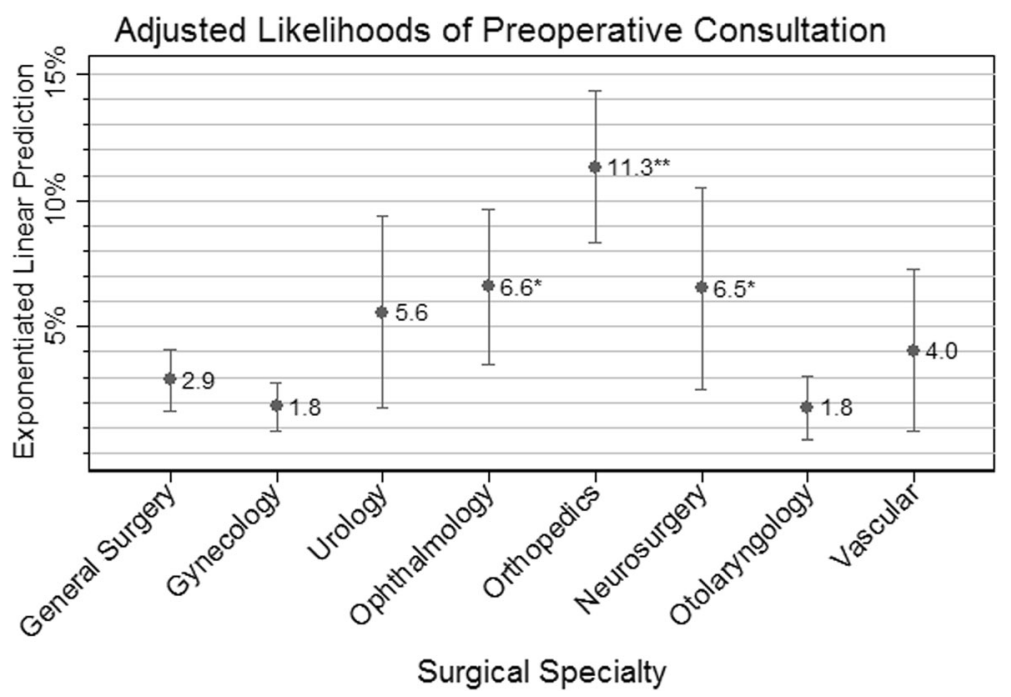

Fig. 2 Adjusted likelihoods of preoperative medical consultation from the main effects model for each surgical specialty. Adjusted for surgical risk, age, gender, Deyo comorbidity score, urban/rural character of patient residence ZIP code, and hospital referral region. General surgery is referent, ${ }^{*} p$ value $=0.02 ;{ }^{* *} p$ value $<0.001$

(Sheffield et al. 2013). Future research is also needed to evaluate the cost consequences of current practice and to determine the role of preoperative consultations.

\section{Limitations}

This study is based on private insurance claims, which may be affected by coding errors or misclassification of preoperative consultation. Consultations most commonly occurred on preoperative days 7 and 14, and with a very low occurrence of visits preceding preoperative day 30 , which suggests that most of these visits were associated with a planned surgery (i.e., low misclassification of unrelated visits as preoperative consultations). Furthermore, this pattern's consistency with prior findings (including our study of an integrated health care system) corroborates the construct validity of our measure of preoperative consultations.

If preoperative medical consultations delayed or canceled surgeries, our data would not include those consultations. However, we believe this limitation is minor, as we used a relatively long, 42-day preoperative window. It is also unknown whether the information resulting from these consultations altered the patient perioperative management. Nevertheless, we have demonstrated that there is a substantial usage of preoperative medical consultation also for patients with limited or no comorbidities, many of whom are undergoing low-risk surgeries. Although this sample is relatively large for studies of preoperative consultation in the US, the sample still had limited power to detect small effects.
The study sample included a small number of vascular surgery and neurosurgery patients, and this limits our ability to draw conclusions specific to these specialties regarding consultations. In the absence of a broad consensus regarding an optimal surgical-risk categorization for all procedures listed, we arbitrarily assigned surgical risk based on similarities with other known procedures in the same categories, and based on clinical judgment. This risk categorization imperfectly differentiates average risk across procedures. We included other covariates to additionally adjust for individual- and geographicspecific factors that predict preoperative consultations, although we could not entirely eliminate selection bias in this observational study.

\section{Conclusions}

In summary, in this study using commercial insurance claims, we found that surgical specialty is associated with the usage of preoperative medical consultation. Although surgical risk strongly predicted usage of consultations, surgical risk did not affect the likelihood of consultation within any individual surgical specialty. Our results extend our previous findings from a study in a single integrated health care system, which also demonstrated variation in preoperative consultation usage by surgical specialty, and found that most consultations were provided for patients with low medical and/or surgical risk. Given these findings, there is a pressing need for outcome studies to evaluate the impact of preoperative medical consultations and guide their optimal use. 


\section{Appendix}

Table $\mathbf{3}$ List of surgical procedures

\begin{tabular}{|c|c|c|c|}
\hline Surgeon specialty and index surgery & No consultation & Had a consultation & $\%$ with a consultation \\
\hline Total & 6915 & 485 & 6.6 \\
\hline Otolaryngology & 448 & 15 & 3.2 \\
\hline Ethmoidectomy and endoscopic sinus surgery' & 440 & 15 & 3.3 \\
\hline Non-endoscopic sinus surgery' & 8 & 0 & 0.0 \\
\hline General surgery & 1670 & 53 & 3.1 \\
\hline Colectomy $^{H}$ & 124 & 8 & 6.1 \\
\hline Exploratory laparotomy ${ }^{\mathrm{H}}$ & 10 & 2 & 16.7 \\
\hline Inguinal hernia repair ${ }^{\mathrm{L}}$ & 327 & 7 & 2.1 \\
\hline Laparoscopic cholecystectomy' & 853 & 25 & 2.8 \\
\hline Mastectomy ${ }^{\mathrm{L}}$ & 306 & 8 & 2.5 \\
\hline Node biopsy ${ }^{\llcorner}$ & 50 & 3 & 5.7 \\
\hline Gynecology & 675 & 12 & 1.7 \\
\hline Dilation and curettage ${ }^{\mathrm{L}}$ & 128 & 1 & 0.8 \\
\hline Hysterectomy ${ }^{\mathrm{H}}$ & 424 & 11 & 2.5 \\
\hline Tubal ligation ${ }^{\mathrm{L}}$ & 123 & 0 & 0.0 \\
\hline Neurosurgery & 113 & 14 & 11.0 \\
\hline Carpal tunnel release $\mathrm{L}^{\mathrm{L}}$ & 4 & 1 & 20.0 \\
\hline Craniotomy ${ }^{\mathrm{H}}$ & 39 & 3 & 7.1 \\
\hline Laminectomy, lumbar' & 70 & 10 & 12.5 \\
\hline Ophthalmology & 945 & 38 & 3.9 \\
\hline Cataract surgery ${ }^{\mathrm{L}}$ & 838 & 30 & 3.5 \\
\hline Ptosis repair ${ }^{\llcorner}$ & 49 & 5 & 9.3 \\
\hline Vitrectomy' $^{\prime}$ & 58 & 3 & 4.9 \\
\hline Orthopedics & 2654 & 317 & 10.7 \\
\hline Carpal tunnel release $\mathrm{L}^{\mathrm{L}}$ & 291 & 12 & 4.0 \\
\hline Femur fracture repair' & 6 & 0 & 0.0 \\
\hline Knee arthroscopy ${ }^{L}$ & 1595 & 105 & 6.2 \\
\hline Laminectomy, lumbar' & 123 & 17 & 12.1 \\
\hline Total hip arthroplasty' & 252 & 70 & 21.7 \\
\hline Total knee arthroplasty' & 387 & 113 & 22.6 \\
\hline Urology & 350 & 29 & 7.7 \\
\hline Laparoscopic radical prostatectomy ${ }^{\mathrm{H}}$ & 60 & 16 & 21.1 \\
\hline Lithotripsy $^{L}$ & 217 & 7 & 3.1 \\
\hline Radical prostatectomy ${ }^{\mathrm{H}}$ & 29 & 3 & 9.4 \\
\hline Transurethral prostatectomy' & 44 & 3 & 6.4 \\
\hline Vascular & 60 & 7 & 10.4 \\
\hline AV fistula' & 24 & 2 & 7.7 \\
\hline Carotid endarterectomy' & 19 & 3 & 13.6 \\
\hline Endovascular AAA repair ${ }^{\mathrm{H}}$ & 3 & 0 & 0.0 \\
\hline Femoro-popliteal bypass ${ }^{\mathrm{H}}$ & 12 & 2 & 14.3 \\
\hline Open AAA repair ${ }^{\mathrm{H}}$ & 2 & 0 & 0.0 \\
\hline
\end{tabular}

Low risk

Intermediate risk

${ }^{\mathrm{H}}$ High risk 


\section{Abbreviations}

CPT: Current Procedural Terminology; GEE: Generalized estimating equation; HRR: Hospital referral region; ICD: International Classification of Diseases; OR: Odds ratio; OR: Oregon; RCRI: Revised Cardiac Risk Index; RUCA: Rural Urban Commuting Area; US: United States; WA: Washington

\section{Funding}

This study was funded by NIH grant T32GM086270 and the Washington State Society of Anesthesiologists, grant recipient Stephan R Thilen.

\section{Availability of data and materials}

The datasets analyzed during the current study are not publicly available due to the Data Use Agreement with Premera Blue Cross, Seattle, WA, but may be made available from the corresponding author on reasonable request.

\section{Authors' contributions}

SRT helped design the study, conduct the study, analyze the data, and write the manuscript. ALW helped analyze and interpret the data and write the manuscript. AMC helped analyze and interpret the data and write the manuscript. EL helped analyze and interpret the data and write the manuscript. EMW helped design the study, interpret the data, and write the manuscript. MMT helped design the study, analyze and interpret the data, and write the manuscript. All authors read and approved the final manuscript.

\section{Ethics approval and consent to participate}

The University of Washington Human Subjects Division reviewed this study and determined that it is not a human subject research.

\section{Consent for publication}

We have permission from Premera Blue Cross insurance company to publish this analysis.

\section{Competing interests}

The authors declare that they have no competing interests.

\section{Publisher's Note}

Springer Nature remains neutral with regard to jurisdictional claims in published maps and institutional affiliations.

\section{Author details}

'Department of Anesthesiology \& Pain Medicine, University of Washington, 325 Ninth Ave, Box 359724, Seattle, WA 98104, USA. ²Department of Health Services, University of Washington, Seattle, WA 98195, USA. ${ }^{3}$ Swedish Medical Center, Seattle, WA 98122, USA. ${ }^{4}$ VA Puget Sound Health Care System, Seattle, WA 98108, USA. ${ }^{5}$ Department of Otolaryngology-Head and Neck Surgery, University of Washington, Seattle, WA 98195, USA. ${ }^{6}$ Department of Anesthesiology and Perioperative Medicine, Oregon Health \& Science University, Portland, OR 97239, USA.

Received: 30 January 2018 Accepted: 6 April 2018

Published online: 04 May 2018

\section{References}

Auerbach AD, Rasic MA, Sehgal N, Ide B, Stone B, Maselli J. Opportunity missed: medical consultation, resource use, and quality of care of patients undergoing major surgery. Arch Intern Med. 2007;167(21):2338-44.

Betensky RA, Talcott JA, Weeks JC. Binary data with two, non-nested sources of clustering: an analysis of physician recommendations for early prostate cancer treatment. Biostatistics. 2000;1(2):219-30.

Clelland C, Worland RL, Jessup DE, East D. Preoperative medical evaluation in patients having joint replacement surgery: added benefits. South Med J. 1996;89(10):958-60

Dartmouth Medical School, Center for the Evaluative Clinical Sciences. The Dartmouth atlas of health care. Chicago: American Hospital Publishing; 1996.

Devereaux PJ, Ghali WA, Gibson NE, Skjodt NM, Ford DC, Quan H, Guyatt GH. Physicians' recommendations for patients who undergo noncardiac surgery. Clin Invest Med. 2000;23(2):116-23.

Deyo R, Cherkin D, Ciol M. Adapting a clinical comorbidity index for use with ICD-9-CM administrative databases. J Clin Epidemiol. 1992;45(6):613-9.
Evaluation ASOATFoP. Practice advisory for preanesthesia evaluation: a report by the American Society of Anesthesiologists Task Force on Preanesthesia Evaluation. Anesthesiology. 2002;96(2):485-96.

Fleisher LA, Beckman JA, Brown KA, Calkins H, Chaikof EL, Fleischmann KE, Freeman WK, Froehlich JB, Kasper EK, Kersten JR, et al. 2009 ACCF/AHA focused update on perioperative beta blockade incorporated into the ACC/ AHA 2007 guidelines on perioperative cardiovascular evaluation and care for noncardiac surgery. J Am Coll Cardiol. 2009;54(22):e13-e118.

Katz R, Barnhart J, Ho G, Hersch D, Dayan S, Keehn L. A survey on the intended purposes and perceived utility of preoperative cardiology consultations. Anesth Analg. 1998;87(4):830-6.

Katz R, Cimino L, Vitkun S. Preoperative medical consultations: impact on perioperative management and surgical outcome. Can J Anaesth. 2005; 52(7):697-702.

Kleinman LC, Norton EC. What's the risk? A simple approach for estimating adjusted risk measures from nonlinear models including logistic regression. Health Serv Res. 2009;44(1):288-302.

Lee T, Marcantonio E, Mangione C, Thomas E, Polanczyk C, Cook E, Sugarbaker D, Donaldson M, Poss R, Ho K, et al. Derivation and prospective validation of a simple index for prediction of cardiac risk of major noncardiac surgery. Circulation. 1999;100(10):1043-9.

Pausjenssen L, Ward H, Card S. An internist's role in perioperative medicine: a survey of surgeons' opinions. BMC Fam Pract. 2008;9:4.

Rosenblatt RA, Hart LG, Baldwin LM, Chan L, Schneeweiss R. The generalist role of specialty physicians: is there a hidden system of primary care? JAMA. 1998; 279(17):1364-70.

Sheffield KM, McAdams PS, Benarroch-Gampel J, Goodwin JS, Boyd CA, Zhang D, Riall TS. Overuse of preoperative cardiac stress testing in medicare patients undergoing elective noncardiac surgery. Ann Surg. 2013;257(1):73-80.

Thilen SR, Bryson CL, Reid RJ, Wijeysundera DN, Weaver EM, Treggiari MM. Patterns of preoperative consultation and surgical specialty in an integrated healthcare system. Anesthesiology. 2013;118(5):1028-37.

Thilen SR, Treggiari MM, Lange JM, Lowy E, Weaver EM, Wijeysundera DN. Preoperative consultations for medicare patients undergoing cataract surgery. JAMA Intern Med. 2014;174(3):380-8.

Wijeysundera DN, Austin PC, Beattie WS, Hux JE, Laupacis A. Outcomes and processes of care related to preoperative medical consultation. Arch Intern Med. 2010;170(15):1365-74.

WWAMI Rural Health Research Center. (n.d.) Rural-Urban Commuting Area Codes (RUCAs). Available at: http://depts.washington.edu/uwruca/. Accessed $24 \mathrm{Apr}$ 2018.

\section{Ready to submit your research? Choose BMC and benefit from}

- fast, convenient online submission

- thorough peer review by experienced researchers in your field

- rapid publication on acceptance

- support for research data, including large and complex data types

- gold Open Access which fosters wider collaboration and increased citations

- maximum visibility for your research: over $100 \mathrm{M}$ website views per year

At BMC, research is always in progress.

Learn more biomedcentral.com/submissions 